\title{
Recuperando a la filosofía de la historia
}

\section{Griselda Gutiérrez Castañeda}

Cruz, Manuel, Filosofía de la bistoria. Barcelona, Paidós básica No. 55, 1991, 189 p.

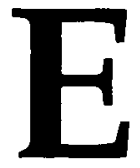

n el libro que ahora comentamos, Filosofia de la bistoria de Manuel Cruz, nos encontramos con una amplia reconstrucción de algunos de los momentos estelares de la filosofía de la historia a través de sus protagonistas más destacados. Ésta es una de las virtudes del libro ya que entrega al lector, especialista o no en el tema, un panorama bastante completo sobre los avatares de esta disciplina filosófica.

Ciertamente, leyendo este libro no deja de experimentarse la extrañeza natural ante tópicos que hace unos años eran tan socorridos por muchos de nosotros, y que por esos virajes en los derroteros del pensamiento, de la propia historia y de la política, devino "a la baja", por usar una expresión del propio autor, como a la baja se pretende que está ahora la política.

Somos muchos los que ahora nos empeñamos por rescatar un lugar para pensar la política, lo cual no es garantía de éxito, pero por lo menos uno disfruta del placer de la compañía; afirmo esto porque no deja de tener su mérito el empeño y la porfía de Manuel Cruz, por mantenerse fiel a un barco que hace rato muchos de nosotros parecería que abandonamos; digo pareceria, porque la reflexión sobre la política está, al fin y al cabo, en más de un lugar ligada a la reflexión filosófica sobre la historia, y a veces más de los que algunos querrian.

A propósito de la interpretación de algunos de esos momentos relevantes en la historia de la filosofía de la historia, hago dos acotaciones muy breves y de detalle: en la lectura que el autor hace de la filosofía de la historia hegeliana, convenimos en que Hegel, frente a Kant y frente al ideal ilustrado, intentará rescatar el momento de lo finito en el devenir histórico, que a decir de Manuel Cruz, queda expresado en la razón de personas finitas, en oposición a una razón natural abstracta. Sin embargo, dicho así, sin más, es una interpretación que puede dar lugar a una lectura de Hegel 
en la que se le adjudica un materialismo y un antropologismo que no son más que subordinados en su pensamiento. Considero que finalmente el principio de inteligibilidad de la historia para Hegel es la plasmación de lo infinito en lo finito. Kierkegaard no estaba desandado cuando cuestionaba la precariedad de lo finito en el idealismo absoluto hegeliano.

Por otra parte, en lo personal, juzgo poco afortunadas las alusiones al tema sobre las implicaciones legitimadoras de un cierto orden o ideales políticos, por parte de algunas variantes de las filosofias de la historia que se nos presentan (Hegel en su momento, y más tarde el historicismo). El tema, sabemos, es espinoso, y si no se contribuye a dar buenas razones que permitan saltar el bache en que nos deja varados la polémica determinismo/indeterminismo, corremos el riesgo de ligereza.

Nos quedaríamos, sin embàrgo, con una falsa imagen de este libro si pensamos que se concreta a la reconstrucción lógica de los argumentos de las distintas modalidades de encarar la explicación de nuestro nexo con el pasado. Hay cuestiones más substanciales dentro de este libro; de manera muy escueta podríamos decir que una de las problemáticas centrales es aquélla en que el autor se hace cargo de los diagnósticos que, desde plataformas distintas, plantean el pretendido fin de la historia (Fukuyama, por sólo mencionar al más reciente). De esta manera intenta revalorar y rescatar un lugar para la historia y para el estudio de ésta, no concibiéndola como un pleno de sentido, cuestión insostenible desde la óptica de los desastres militar, ecológico y político-proyectivos, como tampoco desde el horizonte de las crisis de paradigmas teóricos, sino rescatando en términos posibilistas, y desde la reivindicación de la voluntad, la construcción de fragmentos de sentido, de sentidos posibles que han de buscarse en el futuro, dado el presente abierto que vivimos.

Indudablemente, ésta es la vía en que el autor se aventura por cuenta propia apoyado, si bien entendi, en esta sugerente confluencia ricoeurtiana entre teoria del texto, teoría de la historia y teoría de la acción, y aquí es donde surgen para el lector las interrogantes y los problemas más acuciantes - puntualmente acotados por el autor aquéllos que son más esenciales-, así nos surge la pregunta: si historiografía y narrativa son procedimientos de producción de sentido que tradicionalmente se han guiado por paradigmas teóricos divergentes ¿cómo los hacemos converger sin caer en un mero eclecticismo?

La alternativa propuesta por el autor como puede suponerse, dadas sus fuentes de inspiración, es una teoria de la acción histórica, de la cual se hacen algunos avances, como son la distinción entre tiempo subjetivo y tiempo objetivo, una determinación del concepto de acontecimiento, o 
un rescate de la categoría de sujeto, tamizada, por supuesto, e incorporando las críticas contemporáneas a tal categoría.

Sin embargo, se antoja como necesario un mayor abundamiento, no tan sólo en estos aspectos fenomenológicos que hacen posible pensar cambios radicales para la historiografia, sino, sobre todo, en la propuesta de este nuevo status teórico de la historiografia, es decir, en esta nueva forma de "contar" y de contarnos el acontecer histórico, en esta nueva forma de dar cuenta y de "darnos cuenta" de ese tránsito entre pasado y presente, finalmente no es cualquier viraje el que se está proponiendo al conocimiento histórico.

Pero suponemos que, como corresponde a las obsesiones teóricas, éstas incitarán al autor a continuar avanzando por estos derroteros y que, como lectores, nos hará partícipes de sus nuevos recorridos.

Entre tanto, hago una invitación al público a acercarse a este libro, con la seguridad de que en él encontrarán un material atractivo para la reflexión y con propuestas muy sugerentes, aunque no menos polémicas. 